\title{
Indicadores de sustentabilidade para cultivos de bananeiras em municípios do
}

\author{
Amazonas, Brasil \\ Sustainability indicators for banana crops in municipalities of Amazonas, Brazil \\ Indicadores de sostenibilidad de los cultivos de banano en los municipios de Amazonas, Brasil
}

Recebido: 20/07/2021 | Revisado: 26/07/2021 | Aceito: 02/08/2021 | Publicado: 07/08/2021

\author{
Maricleide Maia Said \\ ORCID: https://orcid.org/0000-0001-6017-8984 \\ GDF, SEMADF, Brasília, Brasil \\ E-mail: mariaid62@gmail.com \\ Maria do Perpétuo Socorro Rodrigues Chaves \\ ORCID: https://orcid.org/0000-0003-4289-2257 \\ Universidade Federal do Amazonas, Brasil \\ E-mail: socorro.chaves@outlook.pt \\ Luiz Antonio de Oliveira \\ ORCID: https://orcid.org/0000-0002-2008-7292 \\ Instituto Nacional de Pesquisas da Amazônia, Brasil \\ E-mail: luiz.oliveira@inpa.gov.br
}

\begin{abstract}
Resumo
Este trabalho apresenta uma proposta para a construção de indicadores de sustentabilidade visando medir a efetividade da integração dos ambientes do sistema produtivo da banana nos municípios de Presidente Figueiredo e Rio Preto da Eva, Amazonas. Ela foi construída a partir da revisão de literatura e de pesquisas de campo realizadas em trinta propriedades rurais produtoras de bananas, localizadas no município de Rio Preto da Eva e quinze em Presidente Figueiredo. Ao final deste trabalho se consolidou as categorias, os elementos, os descritores e os indicadores, orientados para a mensuração da sustentabilidade do sistema produtivo da banana nesses municípios. Para avaliar a sustentabilidade dos cultivos, os indicadores podem ser mensurados a partir das dimensões ambiental, econômica, social, espacial/geográfica, cultural e política. Na Dimensão Ambiental, os indicadores que mais podem afetar a sustentabilidade da bananicultura são o estoque de água nos períodos de estiagem e a necessidade da aplicação de uma adubação dos solos. Na Dimensão Econômica, os indicadores que mais podem afetar são o financiamento da produção, o preço de venda do produto, sua industrialização, o mercado comprador e o escoamento da produção. Na Dimensão Social, os indicadores que mais podem afetar são a saúde, educação e suas participações em Associações/Cooperativas. $\mathrm{Na}$ Dimensão Espacial/Geográfica, os indicadores que mais podem afetar são a falta da posse definitiva da terra e a disponibilidade de recursos hídricos. Na Dimensão Política, poucos são os indicadores usados por essas comunidades, mantendo-as em estádios defasados de desenvolvimento sustentáveis e fragilizadas perante a globalização da economia. Palavras-chave: Sustentabilidade; Desenvolvimento Local; Indicadores de Sustentabilidade.
\end{abstract}

\begin{abstract}
This work presents a proposal for the construction of sustainability indicators to measure the effectiveness of the integration of the environments of the banana production system in the municipalities of Presidente Figueiredo and Rio Preto da Eva, Amazonas. It was built from a literature review and field research carried out in thirty rural properties that produce bananas, located in the municipality of Rio Preto da Eva and fifteen in Presidente Figueiredo. At the end of this work, the categories, elements, descriptors, and indicators were consolidated, aimed at measuring the sustainability of the banana production system in these municipalities. To assess the sustainability of crops, indicators can be measured from the environmental, economic, social, spatial/geographic, cultural, and political dimensions. In the Environmental Dimension, the indicators that can most affect the sustainability of banana production are the water supply in dry periods and the need to apply fertilizer to the soil. In the Economic Dimension, the indicators that can affect the most are the financing of production, the product's sales price, its industrialization, the purchasing market, and the flow of production. In the Social Dimension, the indicators that can most affect are health, education, and their participation in Associations/Cooperatives. In the Spatial/Geographic Dimension, the indicators that can affect the most are the lack of definitive land tenure and the availability of water resources. In the Political Dimension, there are few indicators used by these communities, keeping them in outdated stages of sustainable development and weakened by the globalization of the economy.
\end{abstract}

Keywords: Sustainability; Local Development; Sustainability Indicators. 


\begin{abstract}
Resumen
Este trabajo presenta una propuesta para la construcción de indicadores de sostenibilidad para medir la efectividad de la integración de los ambientes del sistema productivo bananero en los municipios de Presidente Figueiredo y Rio Preto da Eva, Amazonas. Se construyó a partir de una revisión bibliográfica e investigación de campo realizada en treinta propiedades rurales productoras de banano, ubicadas en el municipio de Rio Preto da Eva y quince en Presidente Figueiredo. Al final de este trabajo se consolidaron las categorías, elementos, descriptores e indicadores, orientados a medir la sostenibilidad del sistema productivo bananero en estos municipios. Para evaluar la sostenibilidad de los cultivos, los indicadores se pueden medir desde las dimensiones ambiental, económica, social, espacial / geográfica, cultural y política. En la Dimensión Ambiental, los indicadores que más pueden afectar la sustentabilidad de la producción bananera son el suministro de água en períodos secos y la necesidad de aplicar fertilizantes al suelo. En la Dimensión Económica, los indicadores que más pueden afectar son el financiamiento de la producción, el precio de venta del producto, su industrialización, el mercado de compras y el flujo de producción. En la Dimensión Social, los indicadores que más pueden afectar son la salud, la educación y su participación en Asociaciones / Cooperativas. En la Dimensión Espacial / Geográfica, los indicadores que más pueden afectar son la falta de tenencia definitiva de la tierra y la disponibilidad de recursos hídricos. En la Dimensión Política, son pocos los indicadores utilizados por estas comunidades, lo que las mantiene en etapas desactualizadas de desarrollo sostenible y debilitadas por la globalización de la economía.
\end{abstract}

Palabras clave: Sostenibilidad; Desarrollo Local; Indicadores de Sostenibilidad.

\title{
1 Introdução
}

O crescimento populacional impulsionados pelo modelo de desenvolvimento, sob a égide das relações capitalistas, resultaram numa crise socioambiental em razão do consumo desenfreado de matéria prima para a manutenção dos processos de produção, que demandam uma produção de bens de consumo e de alimentos sem precedentes na história. Como consequência os danos provenientes da exaustão e/ou mau uso dos recursos passaram a fazer parte do nosso cotidiano nos obrigando a repensar as formas de produção e de consumo, especialmente de alimentos, e o uso dos recursos naturais. Nas três últimas décadas, em paralelo, acirraram-se as discussões em torno das questões ambientais e do uso responsável dos recursos naturais (Gupta et al., 2021).

Nesse contexto, mensurar o consumo numa conexão com a conservação dos recursos naturais é imprescindível para a tomada de decisões que primem por evitar desequilíbrios que comprometam ainda mais a capacidade de suporte de recursos do planeta. Dessa forma, é necessária a avaliação sistemática da capacidade de suporte dos recursos naturais como forma de garantir o equilíbrio e a sustentabilidade dos ecossistemas e da vida. Nessa dinâmica, os indicadores desempenham papel importante como instrumento para a mensuração do consumo, da degradação do ambiente, do nível de desenvolvimento econômico, social, político e de suporte geográfico.

No contexto do desenvolvimento, nos diversos quadrantes do planeta, em virtude da utilização desenfreada e predatória dos recursos naturais, evidencia-se a necessidade do uso de indicadores de sustentabilidade. Assim, a Conferência Mundial sobre o Meio Ambiente e Desenvolvimento Humano, Rio 92, caracterizou-se por fortalecer as referências na construção de indicadores de sustentabilidade. Posteriormente, surgiu a necessidade do desenvolvimento de indicadores ecológicos e de sustentabilidade por parte de cada nação, segundo o contexto local. A Agenda $21^{1}$ contribuiu como ponto de partida para o encontro sobre Indicadores Ambientais e Desenvolvimento Sustentável, organizado em Genebra pelo United Nations Environmental Program (UNEP), no ano de 1993, e ao Programa de Indicadores Ambientais, que permite o monitoramento das ações de desenvolvimento (Hammond et al., 1995); além do estudo desenvolvido por Marzall e Almeida (2000), referenciado como marco do estudo de indicadores ocorrido durante o colóquio internacional com o tema Indicador de Sustentabilidade, realizado na França, no ano de 1996.

\footnotetext{
${ }^{1}$ Programa de ação oriundo da Conferência Rio-92 com mais de 2.500 recomendações práticas para o alcance do desenvolvimento sustentável no século XX
} 
Antes da década de 70, os estudos sobre o desenvolvimento, basicamente, atinham-se à utilização e transformação dos recursos e da distribuição dos ganhos por eles proporcionados. A partir desse período os debates nos fóruns mundiais sobre desenvolvimento incluíram a temática da sustentabilidade, mediante as dimensões econômica, social e ambiental. As contribuições de Sachs (1997) nesse debate possibilitaram a inserção de mais duas dimensões do desenvolvimento: a espacial e a cultural. Para este autor, considerado um dos precursores na elaboração do conceito de sustentabilidade, com sua contribuição ao Conferência Mundial sobre Meio Ambiente, realizado em 1972, em Estocolmo, que discutiu o desenvolvimento e os efeitos ambientais $^{2}$, o desenvolvimento perderia o sentido se ocorresse em detrimento da cultura da sociedade.

O conceito de sustentabilidade da relação homem-natureza foi propagado na sociedade a partir da década de 50, mas só foi popularizado durante os anos 80, através das discussões para a consolidação do relatório da Comissão Mundial do Meio Ambiente e Desenvolvimento - CMMAD - de Brundtland ${ }^{3}$, conhecido como "Nosso Futuro Comum", adotado como base para a definição dos princípios da biodiversidade e do futuro das gerações (Sachs, 1993; Montibeller Filho, 2004).

Nesse cenário, o termo sustentabilidade ganhou repercussão atrelado ao desenvolvimento e disseminado mundialmente, sob o lema de que o desenvolvimento permite atender as necessidades presentes sem comprometer a capacidade das gerações futuras de satisfazerem suas próprias necessidades (WCED, 1987). Assim, o desenvolvimento econômico e a utilização dos recursos estão inexoravelmente ligados no tempo e no espaço.

Este trabalho busca identificar indicadores para o desenvolvimento sustentável da cultura da banana nos municípios de Presidente Figueiredo e Rio Preto da Eva, no Amazonas, para que se possa mensurar a sustentabilidade da cultura da banana e dos recursos naturais envolvidos no processo de produção, de forma a permitir o desenvolvimento local.

Assim, o presente trabalho tem como objetivo analisar a bioeconomia como um caminho para a sustentabilidade na Amazônia, por ser promissora em conciliar objetivos sociais, econômicos e ambientais. Para o desenvolvimento da pesquisa, foi utilizada a pesquisa descritiva e bibliográfica. A primeira teve como objetivo descrever as características da bioeconomia, por meio da relação de suas variáveis e condicionantes globais, regionais e locais. A segunda desenvolveu-se com a pesquisa em livros, artigos científicos nacionais e internacionais que visaram entender as diversas concepções do objeto de estudo, a fim de situar o conhecimento da bioeconomia aplicado à Amazônia.

$\mathrm{Na}$ apresentação do conteúdo, o artigo encontra-se dividido em três partes: i) epistemologia ambiental e a ciência econômica; ii) aspectos teóricos da bioeconomia; e iii) bioeconomia: um caminho para a sustentabilidade na Amazônia.

\section{Metodologia}

A pesquisa é de natureza qualitativa, mostrando os indicadores que podem influenciar o cultivo da bananeira no Amazonas, usando como referências, Prodanov \& Freitas (2013), Estrela (2018), Pereira et al. (2018). Para a definição de indicadores visando a sustentabilidade da cultura da banana, primeiramente foram selecionadas as dimensões nas quais se pretendeu fundamentar o estudo. Estas observaram os conceitos de sustentabilidade que, por sua vez, estão vinculados à definição de desenvolvimento. Em seguida definiram-se os objetivos que se pretendeu alcançar e os componentes de estudo para cada dimensão.

A dimensão delimita o estudo em direção ao objetivo que se deseja alcançar. Este, quando alcançado, irá apontar para a sustentabilidade do objeto em análise, que será alcançado, mediante a definição dos componentes para os quais serão definidas as variáveis que serão estudadas. Para a consecução do objetivo deste trabalho, a metodologia de pesquisa compreendeu a

\footnotetext{
${ }^{2}$ Ignacy Sachs preparou o texto p/ reuniões preparatórias - no Centre International de Recherche sur l'Environnement et le Développement (CIRED) com princípios básicos do conceito de Ecodesenvolvimento (SACHS, 1986).

${ }^{3}$ Relatório da Comissão Mundial para o Meio Ambiente e Desenvolvimento (1987) sobre os padrões de desenvolvimento em relação aos recursos naturais.
} 
identificação de indicadores do desenvolvimento sustentável para cultivos de bananeiras nos municípios de Presidente Figueiredo e Rio Preto da Eva, no Amazonas, norteados pelas indicações de Sachs (2008), sobre as cinco dimensões que se configuram como pilares do desenvolvimento sustentável: ambiental, econômica, social, espacial/geográfico e política que se relacionam com a atividade agrícola do cultivo de bananeiras nos municípios alvo da pesquisa. Para cada dimensão foram definidas as categorias, os elementos, os descritores e um conjunto de indicadores que podem ser avaliados para monitoramento da sustentabilidade em cultivos de bananeiras.

Para a definição dos indicadores de sustentabilidade sugeridos para o sistema produtivo de banana nos municípios de Presidente Figueiredo e Rio Preto da Eva, no Amazonas, seguindo as orientações de Daniel (2000), Moura (2002) e Sachs (2004), adotamos os seguintes elementos norteadores:

a) O pressuposto básico adotado foi o conceito de desenvolvimento e sustentabilidade, cujo primeiro deve ser capaz de reduzir ou eliminar as desigualdades por meio da modernidade inclusiva. Enquanto o segundo só se concretizará através de sintonia fina entre as dimensões ambiental, social, econômica, espacial/geográfica e política, envolvendo a análise da capacidade de suporte, os princípios e as exigências de cada dimensão, a fim de alcançar o equilíbrio entre os referenciais do desenvolvimento e da sustentabilidade.

b) Baseia-se no enfoque sistêmico, em nível local, considerando a complexidade dos fenômenos que envolvem o sistema produtivo da banana e observadas as interrelações entre os atores e os indicadores, usando as informações colhidas a partir do trabalho de campo realizados nas comunidades rurais enfocadas por esse estudo.

\subsection{Objeto e Área de Estudo}

Para expressar o estado de sustentabilidade de cada dimensão analisada e identificar suas forças e fragilidades, buscouse definir características estrutural e funcional de cada dimensão e para estas se caracterizou elementos físicos, biológicos e socioeconômicos, espacial e político, observando as categorias indicadas por Sachs (1993), Moura (2002) e Montibeller Filho (2004).

O nível de análise desta pesquisa situa-se na configuração do conjunto de indicadores de sustentabilidade para as dimensões ambiental, econômica, social, espacial e política para o sistema produtivo da banana nos municípios de Presidente Figueiredo e Rio Preto da Eva, no Amazonas. Para cada dimensão foram definidas categorias, elementos, descritores e os indicadores, em acordo com as especificidades locais dos cultivos em estudo.

Os cultivos de bananeiras de 15 propriedades rurais no município de Presidente Figueiredo e 30 no município de Rio Preto da Eva, dentre aquelas de cultivos essencialmente comerciais, foram selecionados e o estudo envolveu as lideranças e associações comunitárias das propriedades investigadas, as agroindústrias relacionadas com o processo de produção da banana, bem como, os canais de distribuição e comercialização da produção, inquirindo, para tanto, os líderes comunitários, presidentes de associações, empresários, proprietários de agroindústrias, intermediários de compra e venda e feirantes envolvidos no processo de comercialização das bananas. Procedeu-se também, a uma pesquisa bibliográfica em sites da internet para consolidar o trabalho.

Quanto ao locus da pesquisa, ambos os municípios pesquisados fazem parte do estado do Amazonas, com população estimada em 3.489.989 habitantes, dos quais 2.755 .490 vivem na área urbana e 728.495 na área rural, distribuídos em 62 municípios (IBGE, 2020). De acordo com o perfil geopolítico das regiões brasileiras, a Região Norte, onde se localiza o estado 
do Amazonas, abrange extensa parte do Bioma Amazônico, ao centro da Amazônia Legal. ${ }^{4}$ Os municípios de Presidente Figueiredo e Rio Preto da Eva estão localizados na Mesorregião do Centro Amazonense.

O município de Rio Preto da Eva dista 79 km ao Norte de Manaus, capital do Amazonas, com população de 5.292 habitantes e área de 347,097 $\mathrm{Km}^{2}$. Enquanto o município de Presidente Figueiredo faz parte da Região Metropolitana de Manaus e ocupa uma área de 25.422,235 km² e com população de 37.193 habitantes (IBGE, 2020).

\subsection{Etapas do Estudo e Técnicas de Construção dos Indicadores de Sustentabilidade}

A descrição das etapas deste estudo teve como finalidade facilitar a compreensão sobre o processo e a lógica de construção dos indicadores e, sobremaneira, o percurso trilhado e as técnicas de pesquisas empregadas para o cumprimento dos objetivos. Primeiro procedeu-se a pesquisa bibliográfica sobre o uso e a construção de indicadores de sustentabilidade para sistemas agrícolas, com a finalidade de identificar os aspectos metodológicos comuns e díspares para a construção de indicadores de sustentabilidade e em quais dimensões se processaria o estudo.

Neste momento, as orientações de Sachs (1993), Moura (2002) e Montibeller Filho (2004) foram fundamentais para definir as dimensões do estudo, as categorias, os elementos e os descritores para a definição do conjunto de indicadores de sustentabilidade. Esta etapa também subsidiou a estruturação do roteiro de entrevista com os produtores rurais da região a fim de identificar os limites básicos do sistema produtivo de banana e os fatores que influenciam sua sustentabilidade.

Considerando os preceitos metodológicos orientados por Moura (2002) e Camino \& Müller (1993), de que os objetivos e metas da avaliação devem considerar o contexto, a definição e os critérios de sustentabilidade adotados, as expectativas dos atores locais, a definição da escala espacial e a viabilidade de obtenção das informações e, ainda, que não existe um indicador ou conjunto de indicadores único aplicável de modo universal, seguiu-se a estrutura metodológica indicada pelos autores, que orientam sete etapas para a definição de indicadores de sustentabilidade, adaptadas para os cultivos de bananeiras nos municípios em estudo, quais sejam: definição do sistema, identificação de categorias significativas para o sistema, identificação dos elementos para cada categoria, seleção dos descritores, definição dos indicadores, análise dos indicadores e procedimentos de monitoramento.

\section{Resultados e discussão}

\subsection{Relação Agricultura, Desenvolvimento e Sustentabilidade}

A agricultura moderna é apontada por muitos autores (Sachs, 1993; Moura, 2002; Montibeller Filho, 2004; Becker, 2009; Mello, 2009) como a alternativa mais promissora para promover o desenvolvimento socioeconômico nas áreas rurais do Brasil. Contudo, ela não deve ser tratada isoladamente, mas sim, aplicada como integrante do processo de sustentabilidade, visto que, conforme adverte Sachs (1993), a sustentabilidade pressupõe o uso racional e equitativo dos recursos de forma a garantir a disponibilidade desses às gerações futuras, visando sempre a melhoria das condições de vida das comunidades.

Orientação semelhante se faz para as práticas de crescimento e desenvolvimento econômico, com o propósito de não igualar os dois conceitos que possuem características bem distintas, visto que o primeiro considera somente o acúmulo de riquezas, embora esta se concentre nas mãos de pequena parcela de indivíduos da população. Este processo não remete à igualdade nem à justiça social. O segundo, por sua vez, preocupa-se com a geração de riquezas sim, mas tem o objetivo de distribuí-las, de melhorar a qualidade de vida das populações, o que remete, portanto, à qualidade ambiental do planeta

\footnotetext{
${ }^{4}$ A Amazônia Legal é composta pelos estados do Acre, Amazonas, Amapá, Pará, Rondônia, Roraima e Tocantins; além de Mato Grosso, parte do Maranhão e ocupa 59\% do território brasileiro e abriga em torno de 24 milhões de habitantes (12\% da população nacional), com 3.853.222,2 km2, sendo a maior extensão territorial que corresponde a aproximadamente 45\% da área total do Brasil. (IBGE, 2016).
} 
(Cavalcanti, 1997). Essa é a ótica do desenvolvimento e deve embasar as discussões atuais sobre a produção de bens e serviços no anseio da equidade social e da sustentabilidade dos recursos naturais em todo o planeta.

A ideia de desenvolvimento local a partir da agricultura, especialmente na região Norte, sugere conciliar os fatores culturais, as tradições locais, a capacidade de suporte dos recursos naturais e as interações econômicas e sociais, de forma interdisciplinar, enfrentando o desafio do binômio agricultura/floresta, de modo que sejam capazes de torná-la produtiva sem destruí-la, exercitando a sustentabilidade.

O conceito de sustentabilidade deve respaldar um processo multidimensional e intertemporal, a ser praticado na escala local, tendo como focos dinamizadores, minimamente, as dimensões ambiental (resiliência), econômica (produtividade) e social (equidade e economia) (Hammond et al., 1995; Sachs, 2004 e Sepúlveda, 2008).

De maneira geral, a sustentabilidade da propriedade rural passa pelo aproveitamento eficaz das áreas cultivadas, procurando obter a melhor produtividade possíveis e, por longos períodos de tempo, diminuindo a necessidade de ocupar novas áreas de florestas. Para que possam dar um retorno financeiro adequado aos produtores, seus usos devem ser pautados em informações de mercado, tendo também, apoio governamental com assistência técnica e para o escoamento da produção, contudo sem comprometer a qualidade dos produtos, a competitividade econômica e a capacidade de suporte dos ecossistemas.

\subsection{Indicadores de Sustentabilidade do Sistema Produtivo da Banana: dimensões, objetivos e componentes}

Os indicadores são detentores de informações sobre a dinâmica dos diferentes tipos dimensionais (Hammond et al., 1995). Na avaliação da sustentabilidade, os indicadores vêm sendo cada vez mais utilizados para mensuração do consumo dos recursos naturais, em função das suas principais consequências nocivas para o meio ambiente, uma vez que o crescimento populacional exige volumes crescentes de matéria prima para manutenção da vida.

O termo indicador implica em inferir, apontar, estimar, conceituando-se como uma variável selecionada e quantificada, fornecendo pistas para problemas, ou tornando perceptíveis tendências ou fenômenos difíceis de serem detectáveis, podendo ser apresentados em forma de dados estatísticos ou gráficos que nos revele traços da realidade e tendências futuras que de outra forma não seria facilmente percebida, permitindo uma aproximação simplificada da realidade observada (Sarandón, 2002). Os indicadores podem ser definidos no âmbito global, nacional, regional ou local. Para o alcance dos objetivos aqui propostos eles serão definidos de acordo com as especificidades locais.

De acordo com Hammond et al. (1995), Sachs (2004) e Sepúlveda (2008), sustentabilidade deve refletir processos multidimensionais e intertemporais, preferencialmente praticados em escalas locais, focando a resiliência, a produtividade, a equidade e economia e, deve ser avaliada por meio de indicadores que permitam a combinação de escalas temporais específicas, a serem definidas de acordo com o sistema avaliado (Christen, 1996), admitindo inúmeras possibilidades, visto que cada sistema possui especificidades.

Entre as diversas possibilidades para a definição das dimensões a serem estudadas, encontram-se as indicadas por Darolt (2000): sociocultural, técnico agronômica, econômica, ecológica e político institucional. Por sua vez, Carvalho (1995) aponta para as dimensões: econômicas, sociológicas, ambientais, políticas, culturais e institucionais. Costabeber (1989) recomenda: econômica, social, ecológica, geográfica e tecnológica, enquanto Camino e Müller (1993) recomendam considerar: justiça social, viabilidade econômica, sustentabilidade ambiental, democracia, solidariedade e ética. Por fim, há as orientações de Sachs (2004) e FAO (2015) pelas dimensões: ambiental, social, econômica, política, cultural e territorial.

Contudo, Sachs (1993) adverte que, para a sustentabilidade de qualquer tipo de sistema que envolva seres humanos, pressupõe-se o uso racional e equitativo dos recursos, sendo fundamental considerar, minimamente, as dimensões econômicas, ambiental e social, como condição precípua para a geração do desenvolvimento no longo prazo, na temporalidade aproximada de 25 anos. 
Para avaliar a sustentabilidade nos cultivos de bananeiras nos municípios de Presidente Figueiredo e Rio Preto da Eva, em acordo com as orientações de Sachs (2004) e Montibeller Filho (2004) os indicadores podem ser mensurados a partir das dimensões social, econômica, ambiental, espacial/geográfica e política. Para cada dimensão devem ser visualizados os componentes e os objetivos que se deseja alcançar para o ambiente estudado. A partir destes foram definidas as variáveis estudadas. Assim, a Quadro 1 apresenta as dimensões sob as quais o desenvolvimento do sistema produtivo da banana pode ser avaliado nos municípios de Presidente Figueiredo e Rio Preto da Eva, no Amazonas, considerando as informações obtidas no trabalho de campo nas comunidades rurais estudadas, bem como os objetivos que se deseja alcançar e os componentes que devem ser avaliados em cada dimensão.

Para esse estudo foram definidas cinco dimensões: ambiental, social, econômica, espacial/geográfica e política (Quadro 1). Para análise da sustentabilidade de cada dimensão foram identificados os objetivos que se deseja alcançar e, para isto, definidos os componentes que devem ser observados, para que, a partir destes, possam ser indicadas as categorias, os elementos, os descritores e os indicadores para cada dimensão analisada. Para a sustentabilidade dos cultivos de bananeiras no Amazonas, o sistema será analisado no âmbito local.

O estudo da sustentabilidade ambiental objetiva a melhoria da qualidade do ambiente e preservação dos recursos naturais e pode ser avaliada por meio: do acompanhamento dos ciclos ecológicos dos ecossistemas, do uso dos recursos naturais não renováveis, da prioridade à produção de biomassa, do aproveitamento dos insumos naturais, da redução do consumo energético, das tecnologias empregadas no sistema produtivo, dos índices de resíduos no processo produtivo, da destinação dos resíduos e cuidados ambientais observados no processo produtivo (Quadro 1). A sustentabilidade da dimensão social visa a redução das desigualdades sociais devendo observar a criação de postos de trabalho, saúde, educação, a disponibilidade de emprego, a renda (distribuição), o respeito à cultura local, o aproveitamento do conhecimento tradicional ou tácito, as formas e níveis de organizações sociais e a produção de bens que favoreçam o atendimento às necessidades básicas das pessoas envolvidas, direta e/ou indiretamente no processo produtivo.

A sustentabilidade na dimensão econômica, que tem por objetivo a melhoria da riqueza social, deve observar o fluxo permanente de investimentos públicos e privados, o manejo dos recursos disponíveis, a capacidade econômica, a capacidade produtiva do cultivo, o aproveitamento dos recursos internos da propriedade, absorção, pela propriedade, dos custos ambientais, a produtividade, o nível de dependência externa e os canais de comercialização (Quadro 1).

A sustentabilidade da dimensão espacial/geográfica objetiva evitar os excessos de aglomeração e, consequentemente, a exaustão dos recursos. Pode ser monitorada pela observação da capacidade de concentração espacial (população), a capacidade endógena de desenvolvimento, a democratização do acesso à terra, a infraestrutura e a capacidade de suporte dos recursos naturais. 
Quadro 1. Dimensões de análise, objetivos e componentes analisados para o desenvolvimento sustentável do sistema produtivo da banana em municípios do Amazonas

\begin{tabular}{|c|c|c|}
\hline Dimensão & Objetivo & Componentes \\
\hline $\begin{array}{l}\text { Sustentabilidade } \\
\text { Ambiental }\end{array}$ & $\begin{array}{l}\text { Melhoria da qualidade do } \\
\text { ambiente e preservação das fontes } \\
\text { de recursos naturais. }\end{array}$ & $\begin{array}{l}\text { Respeito aos ciclos ecológicos dos ecossistemas; } \\
\text { O uso de recursos naturais não renováveis; } \\
\text { Prioridade à produção de biomassa; } \\
\text { Aproveitamento dos insumos naturais; } \\
\text { Redução do consumo de energia; } \\
\text { Tecnologias empregadas no processo produtivo; } \\
\text { Índices de resíduos nos processos produtivos; } \\
\text { Destinação dos resíduos; } \\
\text { Cuidados ambientais; }\end{array}$ \\
\hline $\begin{array}{l}\text { Sustentabilidade } \\
\text { Social }\end{array}$ & $\begin{array}{l}\text { Redução das desigualdades } \\
\text { sociais. }\end{array}$ & $\begin{array}{l}\text { Criação de postos de trabalho; } \\
\text { Saúde; } \\
\text { Educação; } \\
\text { Emprego; } \\
\text { Renda (distribuição); } \\
\text { Cultura local; } \\
\text { Conhecimento tradicional ou tácito; } \\
\text { Organizações sociais; } \\
\text { Produção de bens que favoreçam o atendimento às necessidades básicas; }\end{array}$ \\
\hline $\begin{array}{l}\text { Sustentabilidade } \\
\text { Econômica }\end{array}$ & Melhoria da riqueza social; & $\begin{array}{l}\text { Fluxo permanente de investimentos públicos e privados; } \\
\text { Manejo eficiente dos recursos disponíveis; } \\
\text { Capacidade econômica; } \\
\text { Capacidade produtiva do cultivo; } \\
\text { Aproveitamento dos recursos internos (da propriedade); } \\
\text { Absorção (pela propriedade) dos custos ambientais; } \\
\text { Produtividade; } \\
\text { Redução da dependência externa; } \\
\text { Canais de comercialização; }\end{array}$ \\
\hline $\begin{array}{l}\text { Sustentabilidade } \\
\text { Espacial/ } \\
\text { Geográfica }\end{array}$ & $\begin{array}{l}\text { Evitar excessos de aglomerações e } \\
\text { exaustão dos recursos. }\end{array}$ & $\begin{array}{l}\text { Capacidade de concentração espacial (população); } \\
\text { Capacidade endógena de desenvolvimento; } \\
\text { Democratização do acesso à terra; } \\
\text { Disponibilidade de infraestrutura; } \\
\text { Capacidade de suporte dos recursos naturais; }\end{array}$ \\
\hline $\begin{array}{l}\text { Sustentabilidade } \\
\text { Política }\end{array}$ & $\begin{array}{l}\text { Democratização das políticas } \\
\text { públicas existentes e } \\
\text { fortalecimento da governança; }\end{array}$ & $\begin{array}{l}\text { Criação de leis e políticas para a agricultura; } \\
\text { Organização político institucional; } \\
\text { Democratização da estrutura organizacional existente; } \\
\text { Cooperação institucional e técnica; Governança; }\end{array}$ \\
\hline
\end{tabular}

Fonte: Sachs (2004), Montibeller Filho (2004), adaptado por Said (2015).

A sustentabilidade na dimensão política objetiva a democratização das políticas públicas existentes e as adequações que se fizerem necessárias e, ainda, pelo nível de governança. Pode ser monitorado por meio dos seguintes componentes: criação de Leis e desenvolvimento de políticas para a o fortalecimento da agricultura, as formas e níveis da organização político institucional, a democratização da estrutura organizacional existente, a cooperação institucional e técnica, os níveis de governança na gestão destes componentes e pela apropriação pelo cidadão dos serviços públicos institucionais.

\subsection{Definição de Indicadores de Sustentabilidade para o sistema produtivo da banana}

Até a década de cinquenta, o desenvolvimento foi entendido como sinônimo do crescimento econômico, mensurado por indicadores de ordem estritamente quantitativa. A partir de 1960 acirraram-se as discussões sobre desenvolvimento atrelado à sustentabilidade como caráter indissociável, e os indicadores do desenvolvimento econômico, de ordem meramente quantitativa, tornaram-se insuficientes para aferir o grau de desenvolvimento, visto que não considerava o bem estar social nos diferentes níveis de agregação humana, com melhorias na qualidade de vida da população, a exemplo da diminuição dos níveis de pobreza, 
de desemprego e desigualdade, das condições de saúde, nutrição, educação, moradia, transporte (Sandroni, 1999; Moura, 2002; Cunha, 2006), intensificando as investigações em torno de indicadores capazes de aferir a sustentabilidade em diferentes contextos.

Os conceitos de desenvolvimento e sustentabilidade assumem papel importante no processo de construção dos indicadores de sustentabilidade, bem como na definição das dimensões analisadas, dos objetivos, dos componentes e das variáveis estudadas, revelando o que é importante ser medido e como avaliar e interpretar os resultados (Lopes, 2001). Neste sentido, os indicadores permitirão noções comparativas, visto que um critério é mais ou menos sustentável em dado contexto, não existindo modelos definitivos para cada critério (Moura, 2002). Os indicadores precisam ser os mais específicos possíveis, de modo a se evitar ambiguidades e problemas de validade e confiabilidade, devendo incluir: o objetivo ou a meta a ser alcançado, o aspecto a ser medido, o período abrangido e a área física em questão, devendo também ser mensuráveis, atingíveis, relevantes e oportunos (Guijt, 1999).

Moura (2002) assegura que os objetivos e metas da avaliação devem considerar o contexto, a definição e os critérios de sustentabilidade adotados, as expectativas dos atores locais, a definição da escala espacial e a viabilidade de obtenção das informações. Para Camino \& Müller (1993), devido às características próprias e distintas de cada ecossistema, não existe um indicador ou conjunto de indicadores único aplicável de modo universal. Os autores sugerem uma estrutura metodológica para a definição de indicadores de sustentabilidade, composto de sete etapas, que foram adaptadas para o sistema produtivo da banana (Figura 1).

Figura 1. Sequência metodológica para definição de indicadores de sustentabilidade.

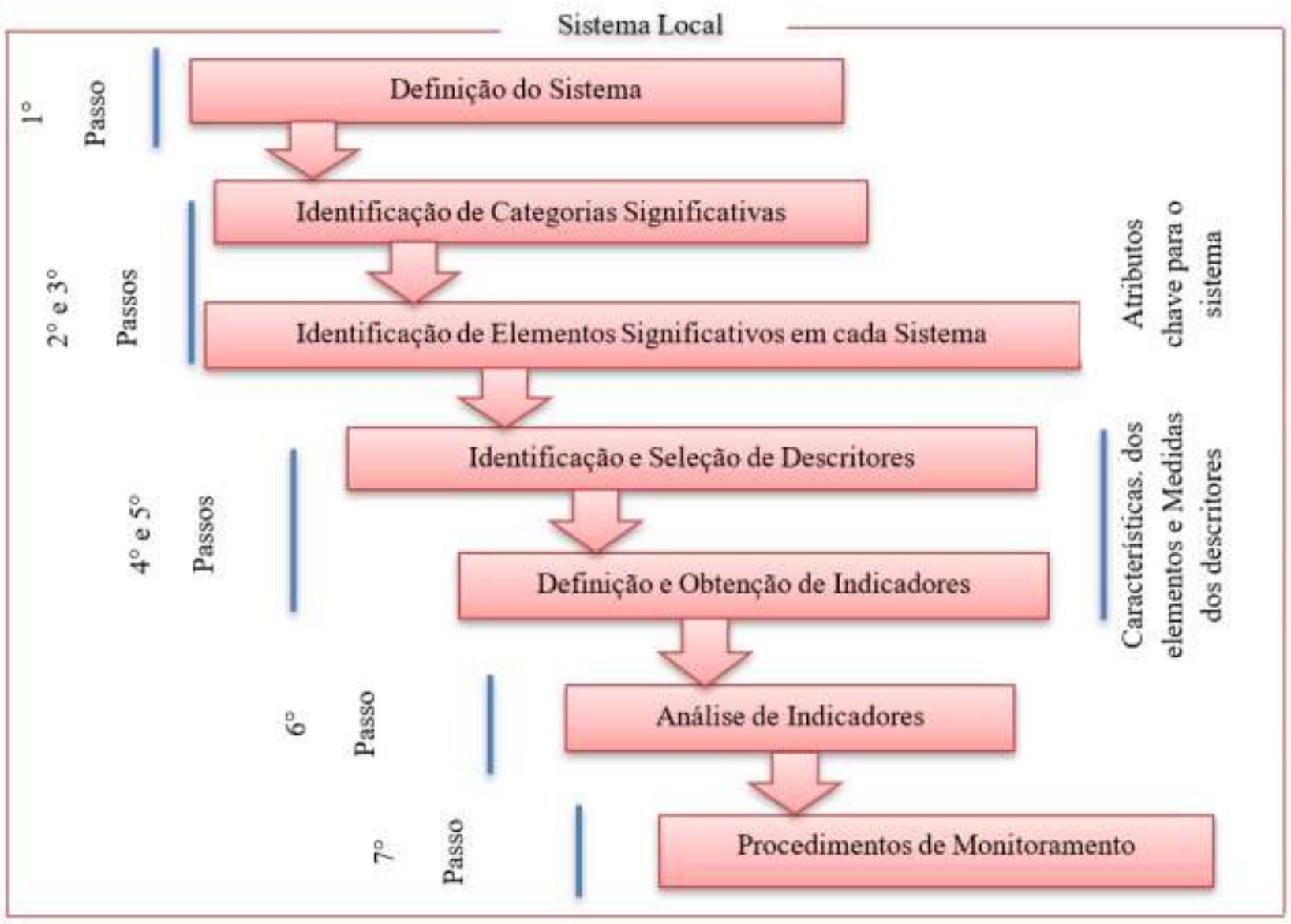

Fonte: Camino e Müller (1993), adaptado por Said (2015). 
As fases dessa sequência metodológica para a definição de indicadores de sustentabilidade, em primeiro passo, orientam que seja determinado o sistema a ser analisado, o qual, segundo Yurjevic (1996), apud Daniel (2000), pode ser delimitado nos níveis global, nacional, regional ou local, permitindo adaptações em acordo com os interesses da avaliação. Para a sustentabilidade do sistema produtivo da banana nos municípios de Presidente Figueiredo e Rio Preto da Eva, no Amazonas, trabalhamos com a delimitação em nível local.

O segundo e terceiro passos, respectivamente, referem-se à identificação das categorias - que é um aspecto do sistema - e dos elementos significativos do sistema - que são parte da categoria - que apresentam significância, dado o grau de influência desses na sustentabilidade do sistema e a importância que eles assumem para a finalidade do estudo. Estas estão atreladas ao que Hansen et al. (1996) e Marzall (1999), apud Lopes (2001), denominam de atributos chave que influenciam na sustentabilidade de cada categoria e, portanto, no sistema geral.

Segundo Ávila (1989), Torquebiau (1989) e Camino \& Müller (1993), apud Daniel (2000), qualquer sistema, em qualquer nível de organização ou agregação pode ser avaliado mediante a análise de quatro tipos de categorias:

- Recursos endógenos: compõem a base de recursos do sistema, ou seja, representam sua estrutura. Os indicadores relacionados a essa categoria devem evidenciar se o sistema impacta negativamente ou se melhora a base de recursos.

- Recursos exógenos: é formada pelos mesmos elementos da categoria dos recursos endógenos; porém, são recursos de sistemas externos com os quais o sistema estudado mantém relações, afetando e sendo afetado por eles. Também compõem a parte estrutural (dos sistemas exógenos).

Operação do sistema: representa a parte funcional do sistema, constituído das atividades necessárias à sua exequibilidade. Os indicadores desta categoria devem mostrar se o seu manejo e desempenho são compatíveis com as exigências da sustentabilidade.

Operação de sistemas exógenos: são atividades fora do sistema necessárias ao seu funcionamento, constituindo sua parte funcional. No sistema produtivo da banana representam os ambientes institucional e organizacional, os fluxos financeiros e de informações que envolvem o sistema e o consumidor (local, regional, nacional e internacional). Estes ambientes comportam o aparato legal de suporte ao sistema em estudo, a disponibilidade de recursos financeiros, humanos e tecnológicos, a assistência técnica, a ciência e tecnologias disponíveis, a infraestrutura disponibilizada, a comercialização da produção, etc.

O quarto e quinto passos, respectivamente, tratam da identificação e seleção dos descritores, que são características relevantes dos elementos selecionados na etapa anterior e subordinam-se aos atributos de sustentabilidade do sistema e ao nível de agregação, e da definição e obtenção de indicadores, que são medidas importantes para esses descritores. A literatura recomenda que para cada descritor relevante, deve-se definir ao menos um indicador. No quinto passo também é realizada a pesquisa de campo.

As etapas sexta e sétima orientam à análise dos indicadores e os procedimentos de monitoramento. Para Daniel (2000), a sexta pode ser subdividida em seis etapas: a) significado do indicador, b) o que, como, onde e quando medir, c) insumos necessários para o cálculo, d) limitações do indicador, e) valores/limites do indicador, f) apresentação e interpretação dos resultados. A sétima pode ter seus procedimentos descritos individualmente para cada indicador ou para todo o conjunto, da forma que melhor responder ao sistema analisado. 


\subsection{Indicadores de Sustentabilidade para Cultivos de Bananeiras nos Municípios de Presidente Figueiredo e Rio Preto}

\section{da Eva, no Amazonas}

O Quadro 2 identifica as categorias, elementos, descritores e indicadores da Dimensão Ambiental visando o cultivo de bananeiras nos municípios de Presidente Figueiredo e Rio Preto da Eva, Amazonas. Na última coluna são mostrados os indicadores a serem trabalhados nessa dimensão, tendo em vista os recursos edafoclimáticos, faunísticos, energéticos, manejo e de luminosidade a serem considerados dentro e fora da propriedade rural.

Nesses parâmetros sobressaem a) a preocupação com o estoque de água nos períodos de estiagem; b) a necessidade da aplicação de uma adubação dos solos nos cultivos, fundamentada em análises químicas e, das necessidades das bananeiras durante o ciclo produtivo. Esses dois parâmetros são considerados os mais importantes tendo em vista a baixa capacidade de retenção de água dos solos predominantes na região (Cochrane et al., 1985; Marques et al., 2010) e a sazonalidade da precipitação pluviométrica (Ribeiro \& Vila Nova, 1979; Salati \& Marques, 1984), como também, pela baixa fertilidade natural dos solos de terra firme da Amazônia (Cochrane et al., 1982; Nicholaides et al., 1983) e o hábito dos produtores não darem importância para a reposição dos nutrientes retirados pela sua produção ou então, por adubarem seus cultivos sem o respaldo de uma análise química dos seus solos, conforme verificado nas pesquisas de campo e outros resultados apresentados por Said (2015).

Quadro 2. Sustentabilidade em sistema produtivo de banana - Dimensão Ambiental.

\begin{tabular}{|c|c|c|c|}
\hline Categoria & Elemento & Descritor & Indicadores \\
\hline \multirow{26}{*}{$\begin{array}{l}\text { Recursos } \\
\text { Endógenos }\end{array}$} & \multirow{6}{*}{ Água } & \multirow[t]{4}{*}{ Quantidade } & Índice da pluviosidade anual $(\mathrm{mm})$ \\
\hline & & & Índice da pluviosidade mensal (mm) \\
\hline & & & Existência de igarapés (sim/não) \\
\hline & & & Reservatórios de água (sim/não) \\
\hline & & \multirow{2}{*}{ Qualidade } & Para consumo humano (sim/não) \\
\hline & & & Para irrigação (sim/não) \\
\hline & \multirow{18}{*}{ Solo } & \multirow[t]{2}{*}{ Classificação } & Tipos de solos \\
\hline & & & Terraceamento (sim/não) \\
\hline & & \multirow[t]{2}{*}{ Conservação } & Preparo mecanizado (sim/não) \\
\hline & & & Estimativa de perda de sedimentos via erosão $\left(\mathrm{t} / \mathrm{h} / \mathrm{a}^{-1}\right)$ \\
\hline & & \multirow{2}{*}{ Microclima } & Umidade do solo $(\%)$ \\
\hline & & & Temperatura do solo $\left({ }^{\circ} \mathrm{C}\right)$ \\
\hline & & \multirow{5}{*}{ Qualidade Química } & Teor de matéria orgânica (\%) \\
\hline & & & Nível de acidez $(\mathrm{pH})$ \\
\hline & & & $\begin{array}{l}\begin{array}{l}\text { Estimativa da perda de nutrientes via lixiviação } \\
\left(\mathrm{kg} / \mathrm{ha}^{-1} \mathrm{a}^{-1}\right)\end{array} \\
\end{array}$ \\
\hline & & & $\begin{array}{l}\begin{array}{l}\text { Estimativa da perda de nutrientes via exportação } \\
\left(\mathrm{kg} / \mathrm{ha} / \mathrm{a}^{-1}\right)\end{array} \\
\end{array}$ \\
\hline & & & Fertilidade (alta/média/baixa) \\
\hline & & \multirow{5}{*}{ Qualidade Física } & Textura (argilosa/siltosa/argilosa) \\
\hline & & & Retenção de água (\%) \\
\hline & & & Erodibilidade (alta/média/baixa) \\
\hline & & & $\begin{array}{lllll}\begin{array}{l}\text { Profundidade da camada } \\
\text { desenvolvimento radicular }(\mathrm{cm})\end{array} & \text { de } & \text { restrição } & \text { ao } \\
\end{array}$ \\
\hline & & & $\begin{array}{l}\text { Índice médio de compactação (densidade aparente, } \\
\mathrm{g} / \mathrm{dm}^{3} \text { ) }\end{array}$ \\
\hline & & Contaminantes & $\begin{array}{l}\text { Aplicação de agrotóxicos com conhecido poder residual } \\
\text { prolongado no solo e com facilidade de lixiviação } \\
\text { (sim/não) }\end{array}$ \\
\hline & & & $\begin{array}{l}\text { Aplicação de resíduos industriais no solo, utilizados } \\
\text { como fertilizantes ou corretivos, que contenham } \\
\text { contaminantes bioacumuladores nocivos (sim/não) }\end{array}$ \\
\hline & \multirow{2}{*}{ Fauna } & \multirow{2}{*}{ Fitossanidade } & Presença de praga (sim/não) \\
\hline & & & Presença de doença (sim/não) \\
\hline
\end{tabular}




\begin{tabular}{|c|c|c|c|}
\hline & & Polinizadores & Presença de polinizadores (sim/não) \\
\hline & \multirow{3}{*}{ Energia } & Solar & Aproveitamento de energia solar ( $\operatorname{sim} /$ não) \\
\hline & & Eólica & Aproveitamento de energia eólica (sim/não) \\
\hline & & Hídrica & Aproveitamento de energia hídrica (sim/não) \\
\hline & \multirow[b]{2}{*}{ Luz } & \multirow[b]{2}{*}{ Radiação } & Temperatura no cultivo $\left({ }^{\circ} \mathrm{C}\right)$ \\
\hline & & & $\begin{array}{l}\text { Interceptação: razão da radiação fotossinteticamente } \\
\text { ativa acima do cultivo/nível do solo }\end{array}$ \\
\hline \multirow{8}{*}{$\begin{array}{l}\text { Recursos } \\
\text { Exógenos }\end{array}$} & \multirow{5}{*}{ Água } & \multirow{3}{*}{ Quantidade } & Índice da pluviosidade anual (mm) \\
\hline & & & Índice da pluviosidade mensal (mm) \\
\hline & & & Existência de igarapés (sim/não) \\
\hline & & \multirow{2}{*}{ Qualidade } & Para consumo humano ( $\operatorname{sim} /$ não) \\
\hline & & & Para irrigação (sim/não) \\
\hline & \multirow{3}{*}{ Fauna } & \multirow{2}{*}{ Fitossanidade } & Presença de praga (sim/não) \\
\hline & & & Presença de doença (sim/não) \\
\hline & & Polinizadores & Presença de polinizadores (sim/não) \\
\hline \multirow{19}{*}{$\begin{array}{l}\text { Operação do } \\
\text { Sistema }\end{array}$} & \multirow{19}{*}{ Manejo Técnico } & \multirow{4}{*}{ Solo } & Presença de cobertura vegetal nativa (sim/não) \\
\hline & & & Presença de cobertura vegetal cultivada ( $\operatorname{sim} /$ não) \\
\hline & & & Presença de erosão (sim/não) \\
\hline & & & Manejo da fertilidade (sim/não) \\
\hline & & \multirow{3}{*}{ Vegetação } & Manutenção da mata nativa (sim/não) \\
\hline & & & $\begin{array}{l}\text { Atende as determinações legais sobre manutenção de } \\
\text { áreas de floresta ( } \operatorname{sim} / \text { não) }\end{array}$ \\
\hline & & & Aproveitamento de resíduos orgânicos (sim/não) \\
\hline & & \multirow{3}{*}{ Água } & Respeita a capacidade de suporte hídrico ( $\operatorname{sim} /$ não) \\
\hline & & & $\begin{array}{l}\text { Manutenção da qualidade dos recursos hídricos } \\
\text { (sim/não) }\end{array}$ \\
\hline & & & Construção de reservatórios (sim/não) \\
\hline & & \multirow{7}{*}{ Resíduos } & $\begin{array}{l}\text { Quantidade de resíduos orgânicos não aproveitados, } \\
\text { depositados direto no sistema (restos vegetais, animais, } \\
\text { etc.) }\left(\mathrm{t} / \mathrm{ha} / \mathrm{a}^{-1}\right)\end{array}$ \\
\hline & & & $\begin{array}{l}\text { Resíduos inorgânicos não aproveitados, depositados } \\
\text { direto no sistema (vasilhames, maquinarias, etc.) } \\
\text { (sim/não) }\end{array}$ \\
\hline & & & $\begin{array}{l}\text { Reciclagem de embalagens de forma direta ou indireta } \\
\text { (sim/não) }\end{array}$ \\
\hline & & & $\begin{array}{l}\text { Correto armazenamento de embalagens de produtos } \\
\text { tóxicos ( } \operatorname{sim} / \text { não) }\end{array}$ \\
\hline & & & Realiza queimadas (sim/não) \\
\hline & & & Tratamento de resíduos (sim/não) \\
\hline & & & Compostagem (sim/não) \\
\hline & & \multirow{2}{*}{$\begin{array}{l}\text { Uso de Recursos } \\
\text { Naturais não } \\
\text { Renováveis }\end{array}$} & Uso de energia elétrica (sim/não) \\
\hline & & & Uso de combustíveis fósseis (sim/não) \\
\hline
\end{tabular}

Fonte: Adaptado por Said (2015).

Ações que minimizem ou sobreponham essas limitações podem favorecer os cultivos de bananeiras nas propriedades rurais, resultando em maiores produtividades e menores impactos ambientais dentro dela, diminuindo os riscos de erosão e exposição direta dos solos ao Sol e chuvas.

Quando se analisa a Dimensão Econômica (Quadro 3) e levando em consideração os resultados já mencionados nos capítulos anteriores que se embasaram nos trabalhos de campo, diversos indicadores devem ser enfatizados quando se pretende atingir determinada sustentabilidade do cultivo de bananeiras nos municípios estudados.

Os indicadores que mais influenciam a sustentabilidade dos cultivos são o financiamento da produção, o preço de venda do produto, o mercado comprador e o escoamento da produção. Os produtores têm muita dificuldade em conseguir financiamento em bancos, em suma, por não ter a posse definitiva da propriedade rural. Como eles tem dificuldades em escoar 
suas produções, ficam reféns dos atravessadores ou então de órgãos governamentais que adquirem sua produção por preços muito baixos, limitando-se também, em comprar apenas parte da colheita.

Além disso, há a necessidade da implantação de agroindústrias para o fortalecimento da cadeia produtiva, tendo em vista um melhor aproveitamento da matéria prima para a produção de subprodutos da banana, bem como da bananeira em si, como doces, geleias, fibras, e outras aplicações industriais (SEBRAE, 2008), reduzindo as perdas que podem atingir $60 \%$ dos frutos, da colheita até o momento do consumo (SEBRAE, 2008; Brasil, 2010).

Quadro 3. Sustentabilidade em sistema produtivo de banana - Dimensão Econômica

\begin{tabular}{|c|c|c|c|}
\hline Categoria & Elemento & Descritor & Indicadores \\
\hline \multirow{19}{*}{$\begin{array}{l}\text { Recursos } \\
\text { Endógenos }\end{array}$} & \multirow{9}{*}{ Financeiro } & \multirow{4}{*}{ Vendas } & Volume de vendas (t/a) \\
\hline & & & Preço de venda do produto (R $\$ /$ penca) - (R\$/cacho) \\
\hline & & & Renda bruta $(\mathrm{R} \$ / \mathrm{a})$ \\
\hline & & & Renda líquida (R\$/a) \\
\hline & & \multirow[t]{5}{*}{ Investimentos } & Infraestrutura (sim/não) \\
\hline & & & Maquinaria (sim/não) \\
\hline & & & Capacitação de recursos humanos (sim/não) \\
\hline & & & Recursos tecnológicos (sim/não) \\
\hline & & & Manejo eficiente dos recursos (sim/não) \\
\hline & \multirow[t]{10}{*}{ Comercialização } & \multirow[t]{2}{*}{ Formas } & Atacado (t/a) \\
\hline & & & Varejo (t/a) \\
\hline & & \multirow{4}{*}{$\begin{array}{l}\text { Canais de } \\
\text { Comercialização }\end{array}$} & Empresas (t/a) \\
\hline & & & Intermediários (t/a) \\
\hline & & & Cooperativas (t/a) \\
\hline & & & Governo (t/a) \\
\hline & & \multirow{4}{*}{ Mercados } & Internacional (t/a) \\
\hline & & & Nacional (t/a) \\
\hline & & & Regional (t/a) \\
\hline & & & Local (t/a) \\
\hline \multirow{21}{*}{$\begin{array}{l}\text { Recursos } \\
\text { Exógenos }\end{array}$} & \multirow[t]{11}{*}{ Financeiro } & \multirow[t]{6}{*}{ Financiamentos } & Fluxo de investimentos privados ( $\mathrm{R} \$ / \mathrm{a})$ \\
\hline & & & Fluxo de investimentos públicos $(\mathrm{R} \$ / \mathrm{a})$ \\
\hline & & & Subvenção (R\$/a) \\
\hline & & & Existência de linhas de crédito específica (sim/não) \\
\hline & & & Disponibilidade de crédito para produtores proprietários (sim/não) \\
\hline & & & $\begin{array}{l}\text { Disponibilidade de crédito para produtores não proprietários } \\
\text { (sim/não) }\end{array}$ \\
\hline & & \multirow[t]{5}{*}{ Investimentos } & Infraestrutura (sim/não) \\
\hline & & & Maquinaria (sim/não) \\
\hline & & & Capacitação de recursos humanos (sim/não) \\
\hline & & & Recursos tecnológicos e instalação de agroindústrias (sim/não) \\
\hline & & & Manejo eficiente dos recursos (sim/não) \\
\hline & \multirow[t]{10}{*}{ Comercialização } & \multirow[t]{2}{*}{ Formas } & Atacado (t/a) \\
\hline & & & Varejo $(\mathrm{t} / \mathrm{a})$ \\
\hline & & \multirow{4}{*}{$\begin{array}{l}\text { Canais de } \\
\text { Comercialização }\end{array}$} & Empresas (t/a) \\
\hline & & & Intermediários (t/a) \\
\hline & & & Cooperativas (t/a) \\
\hline & & & Governo $(\mathrm{t} / \mathrm{a})$ \\
\hline & & \multirow[t]{4}{*}{ Mercados } & Internacional $(\mathrm{t} / \mathrm{a})$ \\
\hline & & & Nacional (t/a) \\
\hline & & & Regional (t/a) \\
\hline & & & Local (t/a) \\
\hline \multirow{6}{*}{$\begin{array}{l}\text { Operação } \\
\text { do Sistema }\end{array}$} & \multirow[t]{6}{*}{ Insumos } & \multirow{6}{*}{$\begin{array}{l}\text { Disponibilidade no } \\
\text { Mercado }\end{array}$} & Fertilizantes químicos (sim/não) \\
\hline & & & Adubos orgânicos (sim/não) \\
\hline & & & Implementos agrícolas (sim/não) \\
\hline & & & Mudas (sim/não) \\
\hline & & & No município (sim/não) \\
\hline & & & No Estado (sim/não) \\
\hline
\end{tabular}




\begin{tabular}{|c|c|c|}
\hline & \multirow{2}{*}{$\begin{array}{l}\text { Status dos Insumos } \\
\text { no Mercado } \\
\text { (aquisição) }\end{array}$} & Na região (sim/não) \\
\hline & & No mercado nacional (sim/não) \\
\hline & \multirow[t]{2}{*}{$\begin{array}{l}\text { Economia de } \\
\text { Recursos }\end{array}$} & $\begin{array}{l}\text { Redução de insumos externos (agrotóxicos, fertilizantes, } \\
\text { embalagens, etc.) (sim/não) }\end{array}$ \\
\hline & & Ampliação do aproveitamento de resíduos (sim/não) \\
\hline \multirow{4}{*}{$\begin{array}{l}\text { Emprego de } \\
\text { Mão de Obra }\end{array}$} & \multirow{2}{*}{ Familiar } & Assalariada (sim/não) \\
\hline & & De subsistência (sim/não) \\
\hline & \multirow[t]{2}{*}{ Contratada } & Temporária/safra (sim/não) \\
\hline & & Permanente (sim/não) \\
\hline \multirow[t]{11}{*}{$\begin{array}{l}\text { Nível } \\
\text { Tecnológico }\end{array}$} & \multirow[t]{5}{*}{ No Cultivo } & $\begin{array}{l}\text { Uso de tecnologias modernas específicas para a formação dos } \\
\text { cultivos (sim/não) }\end{array}$ \\
\hline & & $\begin{array}{l}\text { Uso de tecnologias modernas específicas para a manutenção dos } \\
\text { tratos culturais (sim/não) }\end{array}$ \\
\hline & & Uso de tecnologias modernas específicas para a colheita (sim/não) \\
\hline & & $\begin{array}{l}\text { Uso de tecnologias modernas específicas para o pós-colheita } \\
\text { (sim/não) }\end{array}$ \\
\hline & & Uso de equipamentos modernos (sim/não) \\
\hline & \multirow[t]{4}{*}{ Na Comercialização } & $\begin{array}{l}\text { Uso de tecnologias modernas específicas para o armazenamento } \\
\text { (sim/não) }\end{array}$ \\
\hline & & Uso de tecnologias modernas específicas para o transporte (sim/não) \\
\hline & & $\begin{array}{l}\text { Uso de tecnologias modernas específicas para o controle de estoques } \\
\text { (sim/não) }\end{array}$ \\
\hline & & $\begin{array}{l}\text { Uso de tecnologias modernas específicas para a formação de banco } \\
\text { de dados ( } \operatorname{sim} / \text { não) }\end{array}$ \\
\hline & \multirow{2}{*}{$\begin{array}{l}\mathrm{Na} \text { Transformação } \\
\text { do Produto }\end{array}$} & Processo totalmente mecanizado (sim/não) \\
\hline & & Processo parcialmente mecanizado (sim/não) \\
\hline \multirow{7}{*}{$\begin{array}{l}\text { Comercialização } \\
\text { dos Produtos }\end{array}$} & \multirow[t]{5}{*}{ No atacado } & Supermercados $(\mathrm{kg} / \mathrm{a})$ \\
\hline & & Feiras $(\mathrm{kg} / \mathrm{a})$ \\
\hline & & CEASA $(\mathrm{kg} / \mathrm{a})$ \\
\hline & & Intermediários (kg/a) \\
\hline & & Governo $(\mathrm{kg} / \mathrm{a})$ \\
\hline & \multirow[t]{2}{*}{ No Varejo } & Feiras $(\mathrm{kg} / \mathrm{a})$ \\
\hline & & Na propriedade agrícola $(\mathrm{kg} / \mathrm{a})$ \\
\hline \multirow[t]{14}{*}{ Infraestrutura } & \multirow{3}{*}{$\begin{array}{l}\text { Escoamento da } \\
\text { Produção }\end{array}$} & Estradas asfaltadas (sim/não) \\
\hline & & Estradas de terra (sim/não) \\
\hline & & Fluvial (sim/não) \\
\hline & \multirow{6}{*}{$\begin{array}{l}\text { Transporte da } \\
\text { Produção }\end{array}$} & Veículo terrestre - próprio (sim/não) \\
\hline & & Fluvial - próprio (sim/não) \\
\hline & & Veículo terrestre - do governo (sim/não) \\
\hline & & Fluvial - do governo (sim/não) \\
\hline & & Da cooperativa (sim/não) \\
\hline & & Da associação (sim/não) \\
\hline & \multirow[t]{5}{*}{ Armazenamento } & Veículo terrestre - próprio (sim/não) \\
\hline & & Fluvial - próprio (sim/não) \\
\hline & & Veículo terrestre - próprio (sim/não) \\
\hline & & Veículo terrestre - próprio (sim/não) \\
\hline & & Fluvial - próprio (sim/não) \\
\hline \multirow{7}{*}{$\begin{array}{l}\text { Assistência } \\
\text { Técnica }\end{array}$} & \multirow[t]{3}{*}{ Rural } & Trimestral (sim/não) \\
\hline & & Semestral (sim/não) \\
\hline & & Anual (sim/não) \\
\hline & \multirow[t]{2}{*}{ Financeira } & Semestral (sim/não) \\
\hline & & Anual (sim/não) \\
\hline & \multirow[t]{2}{*}{ Gestão } & Semestral (sim/não) \\
\hline & & Anual (sim/não) \\
\hline $\begin{array}{l}\text { Economia de } \\
\text { Recursos }\end{array}$ & $\begin{array}{l}\text { Redução no } \\
\text { Consumo }\end{array}$ & Insumos de produção (caixas, embalagens, etc.) \\
\hline
\end{tabular}

Fonte: Adaptado por Said (2015). 
Uma análise da Dimensão Social (Quadro 4), considerando as informações obtidas nas propriedades rurais estudadas e nos órgãos envolvidos, aponta que os indicadores que mais afetam a sustentabilidade dos sistemas são: a saúde, educação e suas participações em Associações e Cooperativas. Os serviços de atendimento de saúde são precários, obrigando-os a irem aos centros urbanos para serem atendidos, tendo em vista que apenas em Manaus eles encontram serviços mais sofisticados para a resolução de seus problemas com doenças e afins.

Por outro lado, geralmente eles têm pouco acesso a uma educação consolidada na área rural, precisando enviar seus filhos para escolas nas áreas urbanas do município submetendo-os a grandes dispêndios com deslocamentos, etc. Quanto às suas Associações e Cooperativas, há pouca ou quase nenhuma organização, uma vez que muitas apresentam apenas seus números de CNPJ e uma relação dos associados/cooperados com os nomes e telefones de contato. Algumas contribuem para a comercialização da produção, mas outras nem isso fazem, com cada produtor comercializando sua produção de forma individual.

Quadro 4. Sustentabilidade em sistemas agrícolas de banana - Dimensão Social

\begin{tabular}{|c|c|c|c|}
\hline Categoria & Elemento & Descritor & Indicadores \\
\hline \multirow{10}{*}{$\begin{array}{l}\text { Recursos } \\
\text { Endógenos }\end{array}$} & \multirow{10}{*}{$\begin{array}{l}\text { Desenvolvimento } \\
\text { Cultural }\end{array}$} & \multirow{3}{*}{ Arqueológico } & $\begin{array}{l}\text { Presença de sítio ou vestígio arqueológico na área } \\
\text { dos cultivos (sim/não) }\end{array}$ \\
\hline & & & $\begin{array}{l}\text { Preservação das áreas de sítio arqueológico } \\
\text { (sim/não) }\end{array}$ \\
\hline & & & $\begin{array}{l}\text { Divulgação das áreas de sítio ou de vestígios } \\
\text { arqueológico (sim/não) }\end{array}$ \\
\hline & & \multirow{3}{*}{ Turístico } & $\begin{array}{l}\text { Presença de equipamentos com potencial turístico } \\
- \text { cachoeiras, corredeiras, trilhas, grutas, etc. } \\
(\operatorname{sim} / \text { não) }\end{array}$ \\
\hline & & & $\begin{array}{l}\text { Divulgação dos equipamentos com potencial } \\
\text { turístico - cachoeiras, corredeiras, trilhas, grutas, } \\
\text { etc. ( } \operatorname{sim} / \text { não) }\end{array}$ \\
\hline & & & $\begin{array}{l}\text { Exploração dos equipamentos com potencial } \\
\text { turístico - cachoeiras, corredeiras, trilhas, grutas, } \\
\text { etc. ( } \operatorname{sim} / \text { não) }\end{array}$ \\
\hline & & \multirow[t]{2}{*}{ Artesanal } & $\begin{array}{l}\text { Existência de matéria prima para confecção de } \\
\text { artesanatos (sim/não) }\end{array}$ \\
\hline & & & Confecção de artesanatos (sim/não) \\
\hline & & \multirow[t]{2}{*}{ Patrimônio Religioso } & $\begin{array}{l}\text { Existência de templos ou outras áreas } \\
\text { consideradas sagradas (sim/não) }\end{array}$ \\
\hline & & & Existência de cemitérios (sim/não) \\
\hline \multirow{11}{*}{$\begin{array}{l}\text { Operação do } \\
\text { Sistema }\end{array}$} & \multirow{11}{*}{$\begin{array}{l}\text { Desenvolvimento } \\
\text { Humano }\end{array}$} & \multirow{4}{*}{ Saúde } & Posto médico (sim/não) \\
\hline & & & Hospitais (sim/não) \\
\hline & & & Laboratórios clínicos (sim/não) \\
\hline & & & Clínicas odontológicas (sim/não) \\
\hline & & \multirow{3}{*}{ Educação } & $\begin{array}{l}\begin{array}{l}\text { Escolas de ensino superior } \\
(\text { sim/não) }\end{array} \\
\text { (Faculdades) }\end{array}$ \\
\hline & & & Escolas de ensino médio (sim/não) \\
\hline & & & Escolas de ensino fundamental (sim/não) \\
\hline & & \multirow{4}{*}{ Emprego } & $\begin{array}{l}\text { Criação de postos de trabalho temporário (em } \\
\text { relação ao ano anterior) }\end{array}$ \\
\hline & & & $\begin{array}{l}\text { Criação de postos de trabalho permanente }(\mathrm{em} \\
\text { relação ao ano anterior) }\end{array}$ \\
\hline & & & Garantia dos diretos trabalhistas (sim/não) \\
\hline & & & $\begin{array}{l}\text { Qualificação do trabalho (segundo orientação da } \\
\text { OIT/trabalho decente }{ }^{5} \text { ) }\end{array}$ \\
\hline
\end{tabular}

${ }^{5}$ A Organização Internacional do Trabalho - OIT usa com frequência a expressão "trabalho decente". O adjetivo implica o lado qualitativo: remuneração, condições trabalhistas e relações de trabalho condizentes com a dignidade humana. 


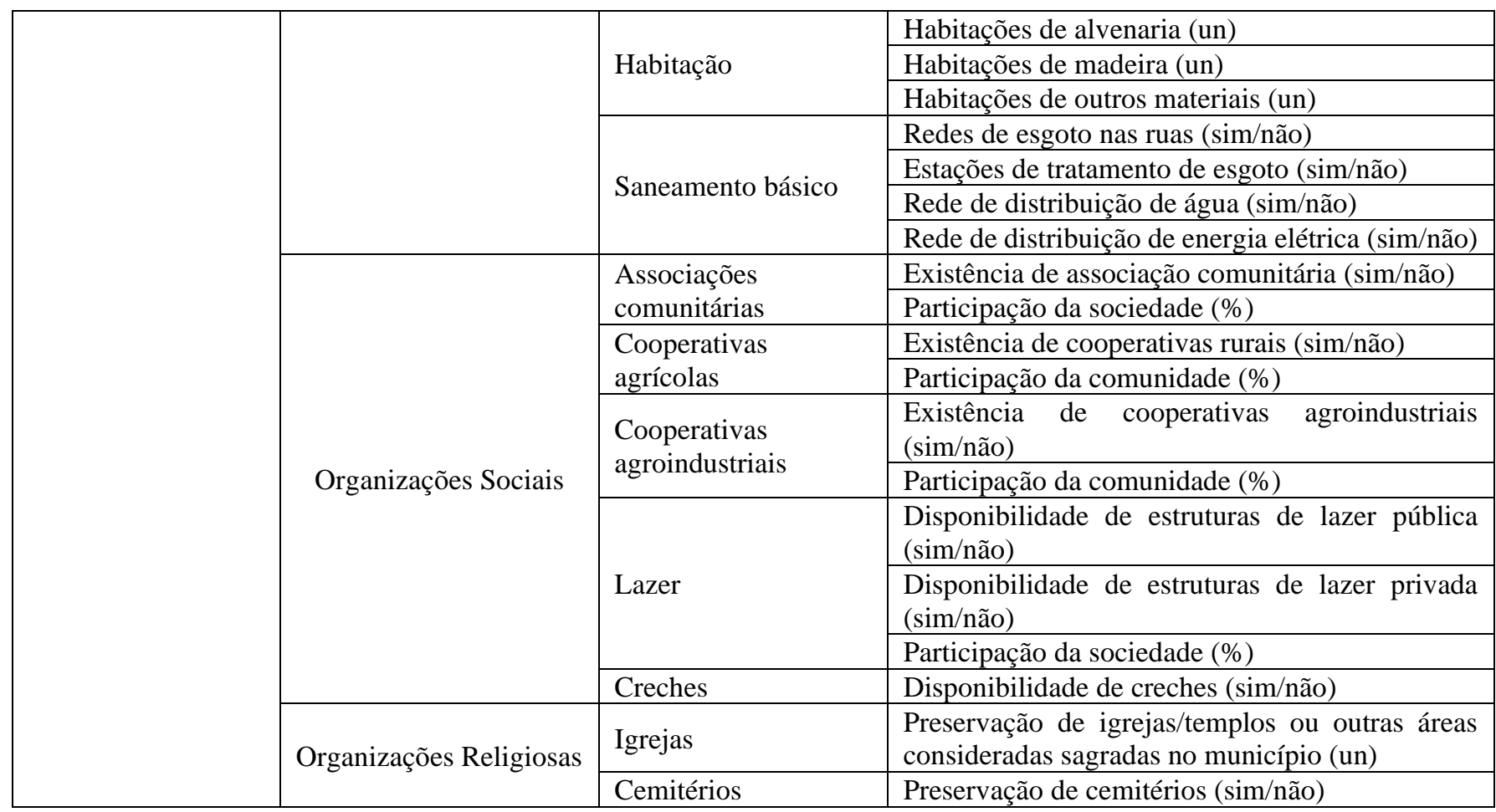

Fonte: Adaptado por Said (2015).

Quanto à Dimensão Espacial/Geográfico (Quadro 5), de todos os indicadores identificados, os mais importantes a serem considerados quando se leva em consideração a sustentabilidade do sistema produtivo são a falta da posse definitiva da terra, problema que aflige a maioria dos produtores e às vezes, à falta de água no período de secas anuais.

Quadro 5. Indicadores de sustentabilidade em sistema produtivo de banana - Dimensão Espacial/Geográfica

\begin{tabular}{|c|c|c|c|}
\hline Categoria & Elemento & Descritor & Indicadores \\
\hline \multirow{8}{*}{$\begin{array}{l}\text { Recursos } \\
\text { Endógenos }\end{array}$} & \multirow{8}{*}{$\begin{array}{l}\text { Recursos } \\
\text { Naturais }\end{array}$} & \multirow[b]{2}{*}{$\begin{array}{l}\text { Ocupação do } \\
\text { Território }\end{array}$} & Propriedade da Terra (sim/não) \\
\hline & & & $\begin{array}{l}\text { Disponibilidade de infraestrutura de acesso à propriedade } \\
\text { (sim/não) }\end{array}$ \\
\hline & & \multirow{4}{*}{ Terra } & Disponibilidade de Terra para a expansão dos cultivos (ha) \\
\hline & & & $\begin{array}{l}\text { Disponibilidade de terra para a introdução de novas culturas } \\
\text { (sim/não) }\end{array}$ \\
\hline & & & Disponibilidade de recursos hídricos (sim/não) \\
\hline & & & Democratização do acesso à terra \\
\hline & & \multirow[t]{2}{*}{ Água } & $\begin{array}{l}\text { Disponibilidade de recursos hídricos naturais - rios, lagos, } \\
\text { igarapés, etc. ( } \mathrm{sim} / \text { não) }\end{array}$ \\
\hline & & & Democratização do acesso à água (sim/não) \\
\hline \multirow{9}{*}{$\begin{array}{l}\text { Operação do } \\
\text { Sistema }\end{array}$} & \multirow{9}{*}{$\begin{array}{l}\text { Manejo dos } \\
\text { Recursos } \\
\text { Naturais }\end{array}$} & \multirow{4}{*}{$\begin{array}{l}\text { Ocupação do } \\
\text { Território }\end{array}$} & Propriedade da Terra (sim/não) \\
\hline & & & Capacidade de concentração espacial $\left(\mathrm{hab} / \mathrm{m}^{2}\right)$ \\
\hline & & & $\begin{array}{l}\begin{array}{l}\text { Capacidade do suporte hídrico } \\
\text { propriedade) }\end{array} \\
\end{array}$ \\
\hline & & & $\begin{array}{l}\text { Infraestrutura disponível (transporte, energia, armazenagem, etc.) } \\
\text { (sim/não) }\end{array}$ \\
\hline & & \multirow{5}{*}{$\begin{array}{l}\text { Recursos } \\
\text { Disponíveis para o } \\
\text { Desenvolvimento }\end{array}$} & Disponibilidade de recursos minerais (sim/não) \\
\hline & & & Disponibilidade de recursos turísticos (sim/não) \\
\hline & & & Disponibilidade de recursos artesanais (sim/não) \\
\hline & & & Disponibilidade de espaços para a comercialização (sim/não) \\
\hline & & & $\begin{array}{l}\text { Disponibilidade de infraestrutura de acesso à propriedade } \\
\text { (sim/não) }\end{array}$ \\
\hline
\end{tabular}


A análise da Dimensão Política (Quadro 6) deve observar os recursos endógenos, exógenos e de operação do sistema produtivo de bananas, com o fim de conhecer quais as forças políticas atuantes no sistema produtivo e a influência destas nos ambientes institucional, organizacional e produtivo e, ainda, entender como se processa os fluxos físicos financeiros e de informações e o nível de governança existente entre os elementos do sistema.

O êxito da dimensão política como elemento de desenvolvimento em determinado território se traduz no conjunto articulado das políticas existentes em nível econômico e social, observadas, preferencialmente, as potencialidades locais, em uma sucessão de operações indissociáveis que se fortalecem à medida que se aprimora a governança entre os atores. Assim, a sustentabilidade da dimensão política aponta para o encadeamento das atividades institucionais, organizacionais e produtivas, dos recursos endógenos, exógenos e de operação do sistema.

Quadro 6. Indicadores de sustentabilidade em sistema produtivo de banana - Dimensão Política.

\begin{tabular}{|c|c|c|c|}
\hline Categoria & Elemento & Descritor & Indicadores \\
\hline \multirow{20}{*}{$\begin{array}{l}\text { Recursos } \\
\text { Endógenos }\end{array}$} & \multirow{20}{*}{$\begin{array}{l}\text { Desenvolvimento } \\
\text { de Políticas } \\
\text { Públicas }\end{array}$} & \multirow{20}{*}{ Municipal } & Uso racional dos recursos hídricos (sim/não) \\
\hline & & & Uso racional da terra (sim/não) \\
\hline & & & Recuperação de áreas degradadas (sim/não) \\
\hline & & & Aproveitamento da energia solar (sim/não) \\
\hline & & & Estímulo à agricultura (sim/não) \\
\hline & & & Infraestrutura direcionada ao setor agrícola (sim/não) \\
\hline & & & Fomento direcionado à agricultura (sim/não) \\
\hline & & & Crédito agrícola (sim/não) \\
\hline & & & Estímulo de incremento da renda no setor agrícola (sim/não) \\
\hline & & & Estímulo para a agregação de valor à produção rural (sim/não) \\
\hline & & & Controle fitopatológico (sim/não) \\
\hline & & & Expansão da comercialização para o mercado internacional (sim/não) \\
\hline & & & Estímulo ao cooperativismo (sim/não) \\
\hline & & & Estímulo ao uso de novas tecnologias (sim/não) \\
\hline & & & Apoio tecnológico para o setor agrícola (sim/não) \\
\hline & & & Assentamento rural (sim/não) \\
\hline & & & Formação de capital intelectual (sim/não) \\
\hline & & & Incentivos fiscais (sim/não) \\
\hline & & & Fiscalização e controle ambiental (sim/não) \\
\hline & & & Controle sanitário \\
\hline \multirow{19}{*}{$\begin{array}{l}\text { Recursos } \\
\text { Exógenos }\end{array}$} & \multirow{19}{*}{$\begin{array}{l}\text { Desenvolvimento } \\
\text { de Políticas } \\
\text { Públicas }\end{array}$} & \multirow{19}{*}{$\begin{array}{l}\text { Federal/ } \\
\text { Estadual }\end{array}$} & Uso racional dos recursos hídricos (sim/não) \\
\hline & & & Recuperação de áreas degradadas (sim/não) \\
\hline & & & Estímulo à agricultura (sim/não) \\
\hline & & & Infraestrutura direcionada ao setor agrícola (sim/não) \\
\hline & & & Fomento direcionado à agricultura (sim/não) \\
\hline & & & Crédito agrícola (sim/não) \\
\hline & & & Estímulo de incremento da renda no setor agrícola (sim/não) \\
\hline & & & Estímulo para a agregação de valor à produção rural (sim/não) \\
\hline & & & Controle fitopatológico (sim/não) \\
\hline & & & Expansão da comercialização para o mercado internacional (sim/não) \\
\hline & & & Estímulo ao cooperativismo (sim/não) \\
\hline & & & Estímulo ao uso de novas tecnologias (sim/não) \\
\hline & & & Apoio às pesquisas relacionadas ao setor agrícola (sim/não) \\
\hline & & & Apoio tecnológico para o setor agrícola (sim/não) \\
\hline & & & Assentamento rural (sim/não) \\
\hline & & & Formação de capital intelectual (sim/não) \\
\hline & & & Incentivos fiscais (sim/não) \\
\hline & & & Fiscalização e controle ambiental (sim/não) \\
\hline & & & Controle sanitário \\
\hline \multirow{3}{*}{$\begin{array}{l}\text { Operação de } \\
\text { Sistemas }\end{array}$} & \multirow{3}{*}{$\begin{array}{l}\text { Execução de } \\
\text { Políticas } \\
\text { Públicas }\end{array}$} & \multirow{3}{*}{$\begin{array}{l}\text { Federal/ } \\
\text { Estadual/ } \\
\text { Municipal }\end{array}$} & Instituição de Ensino Superior - IES (sim/não) \\
\hline & & & Instituição de Ensino Técnico (sim/não) \\
\hline & & & Práticas de inclusão social (sim/não) \\
\hline
\end{tabular}




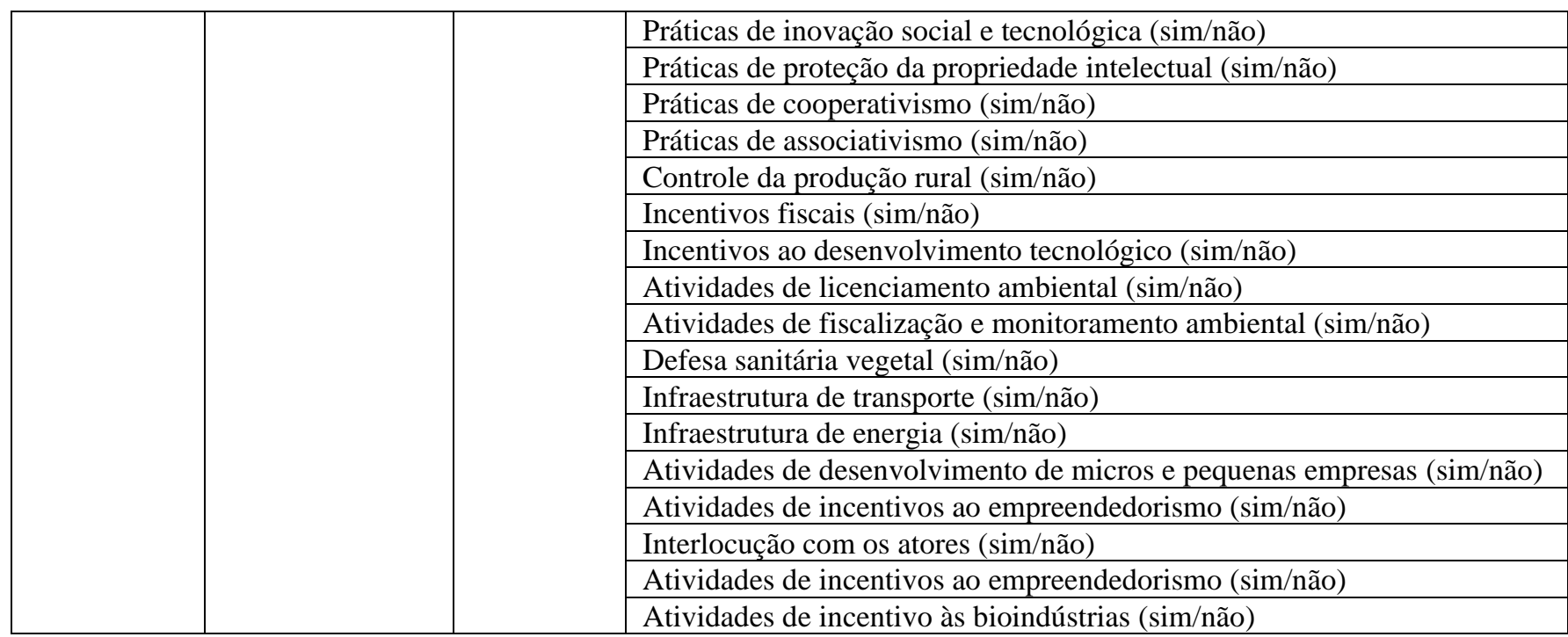

Fonte: Adaptado por Said (2015).

Quando se analisa o Quadro 6 com mais detalhes e se leva em consideração as situações encontradas nas propriedades rurais estudadas, percebe-se que os indicadores de sustentabilidade na Dimensão Política são pouco praticados ou estão ausentes no sistema produtivo de bananas nesses municípios. Essas ausências ou incipiências ocorrem tanto para os recursos endógenos e exógenos, como para os de operação de sistemas. Com raras exceções, os produtores trabalham de forma isolada, com pouco ou nenhum apoio institucional (político) e/ou organizacional (de assistência técnica e/ou financeira), para resolver os problemas em suas propriedades rurais e os que surgem no sistema como um todo.

Os órgãos oficiais apenas esporadicamente visitam suas propriedades para alertar no cumprimento (e fiscalização) das leis ambientais e dando alguma assistência técnica agrícola ou na área de saúde, além de um precário suporte com escolas no nível primário e às vezes no secundário.

Uns dos poucos serviços prestados pelos governos federal, estadual e municipal estão nas áreas de transporte e energia, visto que a maioria das propriedades tem acesso rodoviário. Contudo as estradas que levam às propriedades, em sua maioria, são de terra e de difícil deslocamento, especialmente no período chuvoso. Todas as propriedades analisadas dispunham de energia elétrica, porém, os equipamentos nas propriedades são muito precários, dado o baixo nível de investimentos em tecnologias aplicadas à produção e processamento dos produtos.

Também foi identificada uma razoável assistência por parte das prefeituras municipais no transporte da produção das propriedades rurais até às feiras do próprio município, ou até a capital, que é o maior centro consumidor destes produtos no momento da comercialização, seja no atacado ou no varejo.

O governo do Estado, através do Programa de Regionalização da Merenda Escolar - PREME, em parceria com o governo Federal, também tem significativa participação pela aquisição da produção local. Este fator, se por um lado é de grande valia, por outro, se configura como uma fragilidade do sistema, visto que muitos produtores têm neste canal, a única forma de comercialização da produção no atacado, o que configura uma ameaça potencial ao produtor. Na Dimensão Política, portanto, a maioria dos indicadores definidos no Quadro 6 pode servir de parâmetro para a evolução do sistema produtivo das bananas nos dois municípios.

Portanto, investimentos regionais que visem fortalecer o cultivo da banana no Amazonas podem trazer mais emprego, divisas e desenvolvimento para o Estado. Para isso, ênfases devem ser dadas a indicadores que afetam a cultura dentro das dimensões ambiental, econômica, social, espacial/geográfica, cultural e política (Quadros 2, 3, 4, 5 e 6). 
Na Dimensão Ambiental, os indicadores que mais podem afetar a sustentabilidade dos sistemas produtivos da banana são o estoque de água nos períodos de estiagem e a necessidade da aplicação de uma adubação dos solos nos cultivos fundamentada em análises químicas e, das necessidades das bananeiras durante o ciclo produtivo (Quadro 2).

Na Dimensão Econômica, os indicadores que mais podem afetar a sustentabilidade dos sistemas produtivos da banana são o financiamento da produção, o preço de venda do produto, a industrialização do produto com a implantação de agroindústrias, gerando subprodutos de valor agregado, o mercado comprador e o escoamento da produção (Quadro 3).

$\mathrm{Na}$ Dimensão Social, os indicadores que mais podem afetar a sustentabilidade dos sistemas produtivos da banana são a saúde, a educação e suas participações em associações e cooperativas consolidadas (Quadro 4).

Apesar de haver diversas organizações públicas e privadas no Estado do Amazonas capazes de dar todo o suporte técnico e financeiro para os produtores de bananas obterem altos rendimentos em suas propriedades rurais, a produtividade dessa cultura nos municípios de Presidente Figueiredo e Rio Preto da Eva é bem abaixo daquela considerada desejável (Quadros 1, 5 e 7). Essa baixa produtividade, em torno de 14,5 toneladas por ha ano, poderia pelo menos atingir 50,0 toneladas por ha ano conforme indicação de Arruda et al. (2004), se os produtores tivessem apoio financeiro (Quadros 4 e 7) e orientação técnica no momento da formação dos cultivos (Quadros 3 e 6) que indicassem a ideal densidade de plantas por ha, manejo da fertilidade do solo, do controle das pragas e doenças e, do momento certo para a colheita da produção em seus cultivos. Foi observado em feiras e mercados, bem como in loco em diversas propriedades rurais, a colheita de cachos com frutos ainda sem tamanho e sem padrão, pequenos, que apodrecem antes de amadurecerem.

A falta ou deficiência de financiamentos aos produtores de bananas pelo setor financeiro, geralmente é uma consequência da ausência de documentação de titularidade das propriedades rurais. Sem esses financiamentos, a única forma de se capitalizarem para investirem em tecnologia e melhoria em suas propriedades rurais vem da venda de suas produções de bananas. No entanto, os órgãos governamentais que compram a produção para atender às demandas da merenda escolar pagam muito pouco e compram apenas parte dessa produção, com o restante sendo geralmente vendidos à intermediários do mercado, que pagam um pouco mais, mas ainda não permitindo a esses produtores, se capitalizarem adequadamente para poderem investir melhor em suas propriedades.

Outra limitação quanto à valorização do cultivo da banana na região se refere ao fato de que quase toda sua produção é realizada visando ao consumo in natura. Uma quantidade muito pequena, não mensurável, é convertida em bananas chips, salgada ou doce. A falta de um segmento de processamento da produção (Quadros 5 e 8) para a industrialização da banana na região deixa sua cadeia produtiva fragilizada, com os excedentes sendo perdidos ao invés de gerarem mais empregos e fontes de renda para o Amazonas como um todo.

Devido à fragilidade e à alta perecibilidade da banana, estudos mostram que entre 40 e $60 \%$ do volume produzido da fruta é perdido desde a colheita até o seu consumo. Segundo a Fundação Banco do Brasil (Brasil, 2010), a fase de pós-colheita chega a ser responsável por $60 \%$ das perdas. O desconhecimento das técnicas disponíveis para reduzir as perdas por parte de agentes da cadeia produtiva é a maior causa do desperdício. As principais causas no atacado são a inadequação das embalagens e do armazenamento, bem como o transporte precário das frutas. Por outro lado, no varejo, acredita-se que os mais sérios problemas relacionados às perdas são o tempo entre a compra e venda da fruta e o manuseio inadequado pelo consumidor. Essas perdas poderiam ser reduzidas com o uso de embalagens adequadas e com a colocação dos frutos em câmaras frias com correta temperatura e umidade relativa controlada (SEBRAE, 2008, Brasil, 2010), o que não se observa nas áreas pesquisadas no presente estudo.

A implantação de bioindústrias visando o aproveitamento dos frutos nos dois municípios poderia ser uma saída para a redução das perdas de bananas, além de agregar valor ao produto e fortalecer a cadeia produtiva dessa cultura na região. Segundo SEBRAE (2008), diversos produtos poderiam ser obtidos usando a banana como matéria prima, tais como, banana passa, banana 
chips, doces, tortas, balas, geleias, baby food, cristalizados, iogurte, suco, aguardente, etc. Além disso, existem produtos de uso não alimentar que podem ser obtidos com a planta em si, como fibras da casca da bananeira, artesanato, móveis e objetos de decoração, papel, bananaplac, polímeros naturais e outras aplicações industriais.

Uma importante vantagem no processamento industrial do fruto da banana é a redução das dificuldades logísticas (incluindo transporte e armazenamento), uma vez que os processos de industrialização reduzem peso e volume dos alimentos, além de torná-los menos perecíveis e mais lucrativos. Se esse processamento ocorrer em agroindústrias próximo às áreas de cultivo os resíduos do processamento podem retornar às propriedades e serem convertidos em adubo, evitando danos ao ambiente.

Outro fator positivo em se investir na industrialização da banana é que há uma tendência de fortalecimento do mercado mundial dessa cultura (SEBRAE, 2008; Brasil, 2010), o que pode favorecer o seu cultivo, caso se agregue valores à sua cadeia produtiva.

\section{Considerações Finais}

A partir do estudo efetuado entende-se que para avaliar a sustentabilidade nos cultivos de bananeiras nos municípios de Presidente Figueiredo e Rio Preto da Eva, os indicadores podem ser mensurados a partir das dimensões ambiental, econômica, social, espacial/geográfica, cultural e política.

Na Dimensão Ambiental, os indicadores que mais podem afetar a sustentabilidade dos sistemas produtivos da banana são o estoque de água nos períodos de estiagem e a necessidade da aplicação de uma adubação dos solos nos cultivos fundamentada em análises químicas e, das necessidades das bananeiras durante o ciclo produtivo.

$\mathrm{Na}$ Dimensão Econômica, os indicadores que mais podem afetar a sustentabilidade dos sistemas produtivos da banana são o financiamento da produção, o preço de venda do produto, o mercado comprador e o escoamento da produção.

Os indicadores da Dimensão Social que mais podem afetar a sustentabilidade dos sistemas produtivos da banana são a saúde, educação e a participação da comunidade em Associações e Cooperativas.

$\mathrm{Na}$ Dimensão Espacial/Geográfica, os indicadores mais significativos para a sustentabilidade dos sistemas produtivos da banana são a posse definitiva da terra e a disponibilidade de recursos hídricos.

No âmbito da Dimensão Política, poucos são os indicadores usados pelas comunidades rurais estudadas nos dois municípios, mantendo-as em estádios defasados de desenvolvimento sustentáveis e fragilizadas perante a globalização da economia, especialmente, no que se refere à competitividade.

Por fim, vale enfatizar que este trabalho aglutina a orientação de indicadores de sustentabilidade para as dimensões ambiental, econômica, social, espacial/geográfica e política, sem, contudo, trazer resultados de análise destes indicadores, visto que não se configura objeto deste, que se limita, neste momento, a apresentar uma proposta de indicadores que podem ser utilizados para proceder ao monitoramento dos elementos apresentados em cada dimensão, como forma de mensurar a sustentabilidade do sistema produtivo da banana nos municípios estudados. Estudos futuros, tendo como base esse trabalho, devem ser realizados para detectar a importância de cada um desses indicadores, definindo os que mais contribuem para uma análise qualitativa e quantitativa da cultura da bananeira no Estado do Amazonas e quiçá, na Amazônia brasileira.

\section{Agradecimentos}

Ao CNPq e FAPEAM pelo apoio financeiro para a realização das pesquisas. 


\section{Referências}

Arruda, M. R. de, Pereira, J. C. R., Moreira, A., Pereira, M. C. N., \& Becker, B. K. (2009). Primeiras intervenções. In: Dilemas e desafios do desenvolvimento sustentável no Brasil. (Org.) Nascimento, E. P., Viana, J. N. Rio de Janeiro: Garamond.

Ávila, M. (1989). Sustainability and agroforestry. In: Huxley, P.A. (Ed). Viewpoints and issues on agroforestry and sustainability. Nairobi, Kenya: ICRAF, 9p.

Becker, B.K. (2009). Primeiras intervenções. In: Dilemas e desafios do desenvolvimento sustentável no Brasil. (Org.) Nascimento, E. P.; Viana, J. N. Rio de Janeiro: Garamond.

Brasil. Fundação Banco do Brasil. (2010). Fruticultura. Banana. http://www.bb.com.br/docs/pub/inst/dwn/Vol3FruticBanana.pdf.

Camino, R. \& Müller, S. (1993). Sostenibilidad de la agricultura y los recursos naturales: bases para estabelecer indicadores. San José: IICA, 38.

Carvalho I.C.M. (1995). Movimentos sociais e políticas de meio ambiente. A educação ambiental aonde fica? In: Sorrentino, M.; Trajber, R.; Braga, T. (orgs.). Cadernos do III Fórum de educação ambiental, São Paulo: Gaia, p. 58-62.

Cavalcanti, C. (1997). Meio Ambiente, Desenvolvimento Sustentável e Políticas Públicas. São Paulo: Editora Cortez.

Christen, O. (1996). Sustainable agriculture: history, concept and consequences for research, education, and extension. Berichte Uber Landwirtschaft. 74(1), 66-86. http://www.mendeley.com/research/sustainable-agriculture-history-concept-consequences-research-education-extension/.

Cochrane, T.T., Sánchez, L. G., Azevedo, L. G., Porras, J. A. \& Garver, C. L. (1985). Land in Tropical América. Centro Internacional de Agricultura Tropical (CIAT), Cali. Colômbia (EMBRAPA)-CPCA). Planaltina, D.F. BRASIL.

CMMAD (1998). Comissão Mundial Sobre Meio Ambiente e Desenvolvimento. Nosso Futuro Comum. Rio de Janeiro: FGV.

Costabeber, J. A. (2000). Agroecologia e Desenvolvimento Rural Sustentável: perspectivas para uma Nova Extensão Rural. Revista Agroecologia e Desenvolvimento Rural Sustentável. Porto Alegre-RS: Emater/RS, 1(1):16-37. http://www.emater.tche.br/docs/agroeco/revista.htm.

Christen, O. (1996). Sustainable agriculture: history, concept and consequences for research, education, and extension. Berichte Uber Landwirtschaft, 74(1):6686. http://www.mendeley.com/research/sustainable-agriculture-history-concept-consequences-research-education-extension/.

Cunha, F. L. S. J. (2006). Desenvolvimento, Agricultura e Sustentabilidade. Campinas: CORI/UNICAMP. Sítio da Coordenadoria de Relações Institucionais e Internacionais da Unicamp-CORI. http://www.cori.rei.unicamp.br/CT/resul_trbs.php?cod=291.

Daniel, O. (2000). Definição de Indicadores de Sustentabilidade para Sistemas Agroflorestais. Tese, Universidade Federal de Viçosa. Viçosa - MG, 2000.

Darolt, M. R. (2001). A sustentabilidade do sistema de agricultura orgânica: Um estudo da região metropolitana de Curitiba. Curitiba. http://www.planetaorganico.com.br.

Estrela, C. (2018). Metodologia Científica: Ciência, Ensino, Pesquisa. Editora Artes Médicas.

FAO (2015). Sustainable agriculture. A tool to strengthen food security and nutrition in Latin America and the Caribbean. 2014-2015 highlights. Food and Agriculture Organization of the United Nations. http://www.fao.org/3/i5754e/i5754e.pdf.

Guijt, I. (1999). Monitoramento participativo: conceitos e ferramentas práticas para a agricultura sustentável. Rio de Janeiro: AS-PTA.

Gupta, N., Pradhan, S., Jain, A. \& Patel, N. (2021). Sustainable Agriculture in India 2021. CEEW Report, 122p. https://www.ceew.in/sites/default/files/CEEWFOLU-Sustainable-Agriculture-in-India-2021-20Apr21.pdf

Hammond, A.; Adriaanse, A.; Rodenburg, E.; Bryant, D. \& Woodward, R. (1995). Environmental indicators: a systematic approach to measuring and reporting on environmental policy performance in the context of sustainable development. Washington DC: World Resources Institute.

Hansen, J.W.; Knapp, E.B. \& Jones, J.W. (1996). Determinants of sustainability of a Colombian Hillside farm. Experimental Agriculture, 33(4):425-448.

Lopes, S. B. (2001). Arranjos institucionais e a sustentabilidade de sistemas agroflorestais: uma proposição metodológica. Dissertação (mestrado em Desenvolvimento Rural). Programa de Pós-graduação em Desenvolvimento.

IBGE (2020). Instituto Brasileiro de Geografia e Estatística. http://www.ibge.gov.br/estadosat/temas.php?sigla=am\&tema=lavouratemporaria2012.

IBGE (2016). Instituto Brasileiro de Geografia e Estatística. http://www.ibge.gov.br/estadosat/temas.php?sigla=am\&tema=lavouratemporaria2012.

Lopes, S. B. (2001). Arranjos institucionais e a sustentabilidade de sistemas agroflorestais: uma proposição metodológica. Dissertação (mestrado em Desenvolvimento Rural). Programa de Pós-graduação em Desenvolvimento Rural, UFRGS. Porto Alegre.

Marzall, K.; Almeida, J. (2000). Indicadores de sustentabilidade para Agroecossistemas. Cadernos de Ciência e Tecnologia, 17(1):41-59.

Melo, M. (2009). Primeiras intervenções. In: Dilemas e desafios do desenvolvimento sustentável no Brasil. (Org.) Nascimento, E. P.; Viana, J. N. Rio de Janeiro: Garamond.

Montibeller Filho, G. (2004). O mito do desenvolvimento sustentável: meio ambiente e custos sociais no moderno sistema produtor de mercadorias. 2. ed. Florianópolis: Ed. UFSC, 2004.

Moura, L.G.V. (2002). Indicadores para avaliação da sustentabilidade em sistemas de produção da agricultura familiar: o caso dos fumicultores de Agudo-RS. Dissertação. Programa de Pós-graduação em Desenvolvimento Rural, UFRGS. Porto Alegre. 
Nicholaides, J. J. I., Sanchez, P. A., Bandy D. E., Villachica, J. H., Coutu, A.J. \& Valverde, C.S. (1983). Crop production systems in the Amazon Basin. In: E. MORAN (ed.) The Dilemma of Amazonian Development. Westview.

Pereira, A. S., Shitsuka, D. M., Parreira, F. J. \& Shitsuka, R. (2018). Metodologia da pesquisa científica. Santa Maria/RS. Ed. UAB/NTE/UFSM. https://repositorio.ufsm.br/bitstream/handle/1/15824/Lic_Computacao_Metodologia-Pesquisa-Cientifica.pdf?sequence=1.

Prodanov, C. C. \& Freitas, E. C. (2013). Metodologia do trabalho científico: métodos e técnicas da pesquisa e do trabalho acadêmico. 2. ed. Novo Hamburgo: Feevale,2013. http://www.feevale.br/Comum/midias/8807f05a-14d0-4d5b-b1ad-1538f3aef538/E-ook\%20Metodologia\%20do\%20Trabalho\%20Cientifico.pdf

Ribeiro, M. N. \& Vila Nova, N. A. (1979). Estudos Climatológicos da Reserva Florestal Ducke. Manaus, AM. III. Evaporação. Acta Amazonica, 9:305-309.

Sachs, I. (2004). Desenvolvimento Sustentável: desafio do século XXI. Ambiente \& Sociedade, 7(2). http://dx.doi.org/10.1590/S1414-753X2004000200016.

Sachs, I. (2008). Desenvolvimento: includente, sustentável e sustentado. Rio de janeiro: Garamond.

Sachs, I. (1997). Desenvolvimento numa economia mundial liberalizada e globalizante: um desafio impossível? Estudos Avançados,11(30). DOI:10.1590/S0103-40141997000200014

Sachs, I. (1993). Estratégias de Transição para o Século XXI: desenvolvimento e meio ambiente. Tradução Magda Lopes. São Paulo: Studio Nobel: Fundação do desenvolvimento administrativo.

Sachs, I. (1986). Ecodesenvolvimento: crescer sem destruir. São Paulo: Vértice.

Said, M. M. (2015). Práticas de Gestão e Indicadores de Sustentabilidade em Cultivos de Bananas no Estado do Amazonas. Tese de Doutorado, PPGBIOTEC/UFAM.

Salati, E. \& Marques, J. (1984). Climatology of the Amazon Region. In The Amazon - Limnology and Landscape Ecology of a Mighty Tropical River and its Basin. In: Sioli, H. (ed.). Dr. W. Junk Publishers, 1984.

Sandroni, P. (1999). Novíssimo Dicionário de Economia. São Paulo: Editora BestSeller.

SEBRAE. (2008). Banana. Estudos de Mercado. SEBRAE/ESPM. https://docplayer.com.br/8728548-Banana-estudos-de-mercado-sebrae-espm-2008sumario.html

Sepúlveda, S. S. (2008). Biograma: metodología para estimar el indice de desarrollo sostenible de territorios. San José, C.R.: IICA.

Torquebiau, E. (1989). Sustainability indicators in agroforestry. In: Huxley, P.A. (Ed.). Viewpoints and issues on agroforestry and sustainability. Nairobi, ICRAF. $14 \mathrm{p}$

WCED -World Commission on Environment and Development (1987). Our common future. Oxford: Oxford University Press, 1987. 400p.

Yurjevic, A. (1996). El desarrollo sustentable: una mirada actualizada. Agroecología y Desarrollo, Santiago, 10:10-17. 